\title{
Inpatient morbidity and mortality after adult spinal deformity surgery in teaching versus nonteaching hospitals
}

\author{
Rafael De la Garza-Ramos, MD, ${ }^{1}$ Amit Jain, MD, ${ }^{2}$ Khaled M. Kebaish, MD, ${ }^{2}$ Ali Bydon, MD, ${ }^{1}$ \\ Peter G. Passias, MD, ${ }^{3}$ and Daniel M. Sciubba, MD ${ }^{1}$
}

Departments of ${ }^{1}$ Neurosurgery and ${ }^{2}$ Orthopaedic Surgery, Johns Hopkins University School of Medicine, Baltimore, Maryland; and ${ }^{3}$ Division of Spinal Surgery, NYU Medical Center Hospital for Joint Diseases, New York, New York

OBJECTIVE The goal of this study was to compare inpatient morbidity and mortality after adult spinal deformity (ASD) surgery in teaching versus nonteaching hospitals in the US.

METHODS The Nationwide Inpatient Sample was used to identify surgical patients with ASD between 2002 and 2011. Only patients > 21 years old and elective cases were included. Patient characteristics, inpatient morbidity, and inpatient mortality were compared between teaching and nonteaching hospitals. A multivariable logistic regression analysis was performed to examine the effect of hospital teaching status on surgical outcomes.

RESULTS A total of 7603 patients were identified, with $61.2 \%(n=4650)$ in the teaching hospital group and $38.8 \%(n=$ 2953 ) in the nonteaching hospital group. The proportion of patients undergoing revision procedures was significantly different between groups $(5.2 \%$ in teaching hospitals vs $3.9 \%$ in nonteaching hospitals, $p=0.008)$. Likewise, complex procedures (defined as fusion of 8 or more segments and/or osteotomy) were more common in teaching hospitals ( $27.3 \%$ vs $21.7 \%, p<0.001)$. Crude overall complication rates were similar in teaching hospitals $(47.9 \%)$ compared with nonteaching hospitals $(49.8 \%, p=0.114)$. After controlling for patient characteristics, case complexity, and revision status, patients treated at teaching hospitals were significantly less likely to develop a complication when compared with patients treated at a nonteaching hospital $(\mathrm{OR} 0.89 ; 95 \% \mathrm{Cl} 0.82-0.98)$. The mortality rate was $0.4 \%$ in teaching hospitals and $<0.4 \%$ in nonteaching hospitals $(p=0.210)$.

CONCLUSIONS Patients who undergo surgery for ASD at a teaching hospital may have significantly lower odds of complication development compared with patients treated at a nonteaching hospital.

http://thejns.org/doi/abs/10.3171/2015.11.SPINE151021

KEY WORDS adult spinal deformity; teaching hospital; Nationwide Inpatient Sample; complications; mortality

A DULT spinal deformity (ASD) is a common spinal disorder in patients over 60 years of age, with studies suggesting prevalence as high as $68 \% .{ }^{17}$ Although corrective surgery achieves better outcomes in terms of leg pain and disability compared with nonoperative treatment, ${ }^{15,19}$ complication rates range from $37 \%$ to $78 \%$ in the literature..$^{1,3,9,18}$ Risk factors for complication development include age over 65 years, longer constructs, female sex, revision procedures, and having surgery performed by a low-volume surgeon or at a low-volume hos-

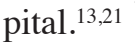

Recently, attention has been given to the role that teaching hospitals play in outcomes after spinal surgery. Although teaching hospitals claim better quality of care than nonteaching hospitals ${ }^{20}$ there have been conflicting data when examining outcomes specifically in degenerative spine disease cases. ${ }^{6,12}$ Fineberg et al. demonstrated significantly higher complication rates for patients undergoing cervical spine operations for myeloradiculopathy at teaching versus nonteaching hospitals. ${ }^{6}$ Likewise, Nandyala et al. found higher complication rates in teaching versus nonteaching hospitals for patients undergoing lumbar spine operations. ${ }^{12}$ Interestingly, both of these studies attributed this to differences in case complexity and patient comorbid conditions.

Despite these findings, there are limited data on the impact of teaching status on inpatient outcomes after surgery for ASD. Thus, the purpose of this study was to investigate

ABBREVIATIONS ASD = adult spinal deformity; LOS = length of stay; NIS = Nationwide Inpatient Sample.

SUBMITTED August 25, 2015. ACCEPTED November 3, 2015.

INCLUDE WHEN CITING Published online March 4, 2016; DOI: 10.3171/2015.11.SPINE151021. 
whether patients with ASD who undergo surgery have different short-term outcomes when treated at a teaching versus a nonteaching hospital.

\section{Methods}

\section{Study Design and Data Source}

This is a retrospective study of a prospectively collected national database, the Nationwide Inpatient Sample (NIS), for the years 2002-2011. The NIS is one of the largest national inpatient databases available to the public and provides inpatient data from approximately 8 million admissions each year. This database is a $20 \%$ sample database of all discharges in the US stratified by geographical region, metropolitan location, hospital teaching status, and hospital size. Data are prospectively collected at participating hospitals, and de-identified information is then captured.

\section{Inclusion and Exclusion Criteria}

Diagnostic codes from the International Classification of Diseases, Ninth Revision, Clinical Modification (ICD-9-CM) were used to identify patients with scoliosis. Only patients who presented with one of the following codes were included: acquired postural kyphosis (737.10), kyphosis not elsewhere classified (737.19), acquired postural lordosis (737.20), idiopathic scoliosis and kyphoscoliosis (737.30), progressive infantile idiopathic scoliosis (737.32), thoracogenic scoliosis (737.34), scoliosis not elsewhere classified (737.39), kyphosis from secondary cause (737.41), lordosis from secondary cause (737.42), and kyphoscoliosis from secondary cause (737.43). Patients undergoing surgery were then identified if they included any of the following procedural codes for spinal arthrodesis: 81.04-81.09 (Fig. 1). Patients younger than 21 years of age, patients with nonelective admissions, and admissions not reporting hospital teaching status were excluded.

\section{Covariate Data}

Admission information such as patient age, sex, race, comorbidities, primary payer, diagnosis, procedures performed, and other data were collected from the database. Complex cases were defined as those involving fusion of 9 or more vertebrae (8 or more spinal segments) and/or cases involving osteotomy (vertebral osteotomy: 77.39 or vertebral wedge osteotomy: 77.29). Revision procedures were also identified by the use of Codes $81.3,81.34,81.35$, 81.36, 81.37, 81.38, and 81.39.

All identified discharges were divided into 2 groups: teaching and nonteaching hospitals. According to the NIS, a hospital is considered a teaching hospital if it has an American Medical Association-approved residency program, is a member of the Council of Teaching Hospitals, or has a ratio of interns and residents to beds of 1 to 4 or higher (https://www.hcup-us.ahrq.gov/db/vars/ hosp_teach/nisnote.jsp).

\section{Outcome Measures}

Outcome measures included inpatient morbidity (defined as the development of at least 1 complication), inpa-

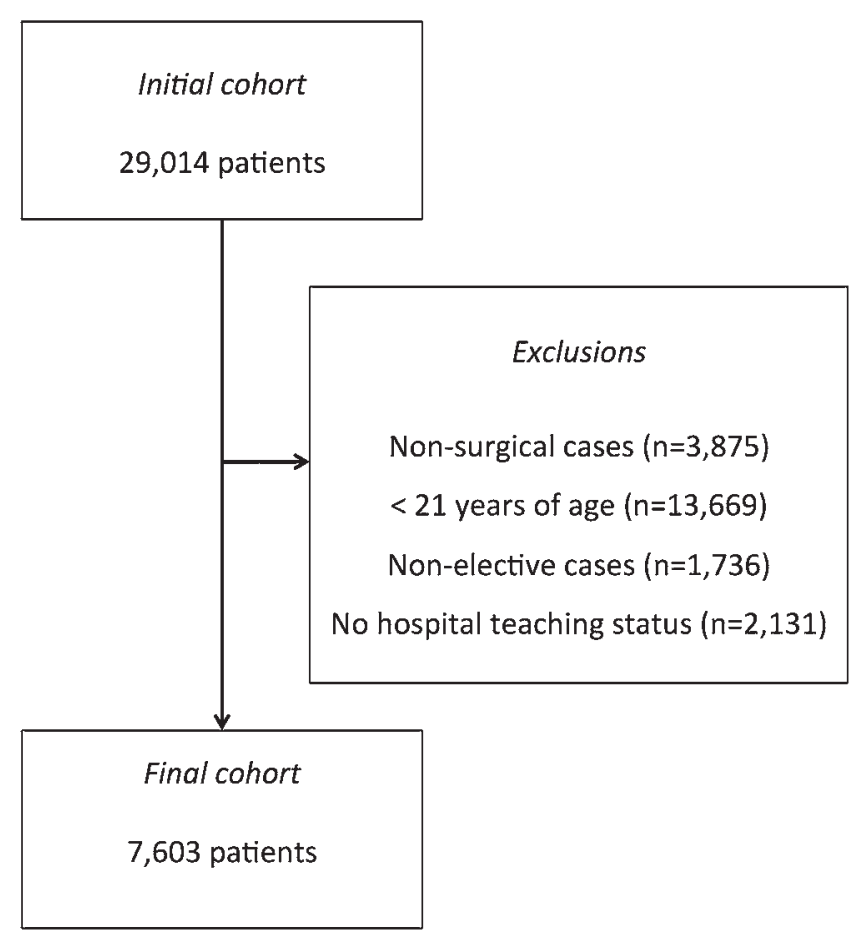

FIG. 1. Patient inclusion/exclusion algorithm.

tient mortality, and length of stay (LOS). Complications examined included postoperative shock (998.00-998.09), acute posthemorrhagic anemia (285.1), neurological complication (997.00-997.09), acute respiratory failure (including adult respiratory distress syndrome; 518.5-518.53, 518.81, 518.84, 997.3), implant-related complications (996.2, 996.40, 996.42, 996.47, 996.49, 996.63, 996.66, 996.67, 996.75, 996.78, and 996.79), incidental durotomy (349.31 and 349.39), wound complications (998.83, 998.32, 998.51, 998.59, and 998.6), venous thromboembolism (453.4-453.42, 453.8, 453.9, 415.22, 415.13, and 415.19), accidental puncture (998.2), hemorrhage or hematoma (998.11-998.13), acute kidney injury (584.5-584.9), myocardial infarction (410.0-410.91), pneumonia $(481,482$, and 483), iatrogenic stroke (997.02), and pancreatitis (557.0). The following were subcategorized as procedure-related complications: hemorrhage or hematoma, implant-related complication, accidental puncture, acute posthemorrhagic anemia, wound complication, neurological complication, and iatrogenic stroke.

\section{Statistical Analysis}

All analyses were performed using Stata/SE 12 (StataCorp LP). General demographic data and outcomes were compared between teaching and nonteaching groups. Continuous data were compared via the unpaired t-test with unequal variances, and categorical data were compared via the chi-square or Fisher's exact test as appropriate. A binary logistic regression analysis was performed to identify the independent effect of hospital teaching status on inpatient morbidity and mortality. Regression analyses were adjusted for patient age ( $>65$ years), sex, comorbidities (congestive heart failure, chronic lung disease, coagu- 
lopathy, diabetes, obesity, liver disease, and renal failure), primary payer, case complexity, revision status, and diagnosis. Statistical significance was set at $\mathrm{p}<0.05$.

\section{Results}

A total of 7603 elective admissions of patients who underwent surgery for ASD were identified, and their data are summarized in Table 1. There were 4650 (61.2\%) patients treated at a teaching hospital and 2953 (38.8\%) patients treated at a nonteaching hospital. Patients treated at nonteaching hospitals were significantly older compared with patients treated at teaching hospitals (62 vs 59 years, $\mathrm{p}<0.001$ ). Significantly different comorbidities between groups included rates of chronic lung disease and diabetes.

The primary payer was significantly different between groups, with a higher proportion of patients in the nonteaching hospital group having Medicare $(53.7 \%$ vs $45.6 \%$ ) and a higher proportion of patients in the teaching hospital group having private insurance ( $46.2 \%$ vs $41.2 \%$ ). The proportion of patients with complex procedures was significantly higher in the teaching hospital group (27.3\%) compared with the nonteaching hospital group $(21.7 \%$, p $<0.001)$. Likewise, the percentage of patients undergoing revision procedures was significantly different between groups $(5.2 \%$ in teaching hospitals vs $3.9 \%$ in nonteaching hospitals, $\mathrm{p}=0.008$ ). The most common diagnosis in both groups was idiopathic scoliosis, which accounted for $57.7 \%$ of cases in teaching hospitals and $63.2 \%$ in nonteaching hospitals $(\mathrm{p}<0.001)$.

\section{Outcomes and Complications}

The LOS was significantly different between groups, with patients in the teaching hospital group staying on average 7.0 days compared with 5.2 in nonteaching hospitals $(\mathrm{p}<0.001)$ (Table 2). The overall complication rate was $48.7 \%$; $47.9 \%$ in teaching hospitals versus $49.8 \%$ in nonteaching hospitals $(\mathrm{p}=0.114)$. Procedure-related complications occurred in $40.8 \%$ of patients in teaching hospitals compared with $42.8 \%$ in nonteaching hospitals $(\mathrm{p}=0.078)$. Last, mortality rates were also not different between groups $(0.4 \%$ in teaching hospitals vs $<0.4 \%$ in nonteaching hospitals, $\mathrm{p}=0.210$ ).

The most common complication was acute posthemorrhagic anemia in $34.8 \%$ of patients, followed by acute respiratory failure in $8.5 \%$ of patients, and implant-related complications in $7.4 \%$ of patients (Table 3). Acute posthemorrhagic anemia was significantly more prevalent in nonteaching hospitals (36.8\%) compared with teaching hospitals $(33.5 \%, p=0.003)$. Likewise, incidental durotomy was more common in nonteaching hospitals (5.7\%) compared with teaching hospitals $(4.4 \%, \mathrm{p}=0.007)$. On the other hand, deep vein thrombosis was more common in teaching hospitals $(1.5 \%)$ versus nonteaching hospitals $(0.5 \%, \mathrm{p}<0.001)$, as were wound-related complications $(1.2 \%$ in teaching hospitals vs $0.6 \%$ in nonteaching hospitals, $\mathrm{p}=0.020)$ and respiratory complications $(9.1 \%$ in teaching hospitals vs $7.6 \%, p=0.020$ ). Other major medical complications such as acute kidney injury, myocardial infarction, pneumonia, and pancreatitis were not significantly different between groups.
TABLE 1. General characteristics of patients undergoing surgery for ASD at teaching versus nonteaching hospitals between 2002 and 2011

\begin{tabular}{|c|c|c|c|}
\hline Parameter & $\begin{array}{l}\text { Teaching } \\
\text { Hospital* }^{*}\end{array}$ & $\begin{array}{l}\text { Nonteaching } \\
\text { Hospital* }^{*}\end{array}$ & p Value \\
\hline No. of cases & 4650 & 2953 & \\
\hline Age in yrs, average \pm SD & $59 \pm 15$ & $62 \pm 14$ & $<0.001$ \\
\hline Female sex & 74.1 & 72.4 & 0.112 \\
\hline \multicolumn{4}{|l|}{ Comorbidities } \\
\hline Congestive heart failure & 2.4 & 2.2 & 0.585 \\
\hline Chronic lung disease & 15.6 & 18.2 & 0.003 \\
\hline Coagulopathy & 8.1 & 8.8 & 0.278 \\
\hline Diabetes & 9.5 & 12.0 & 0.001 \\
\hline Liver disease & 1.1 & 0.8 & 0.196 \\
\hline Obesity & 8.2 & 8.8 & 0.358 \\
\hline Renal failure & 2.8 & 2.4 & 0.219 \\
\hline \multicolumn{4}{|l|}{ Race } \\
\hline Caucasian & 91.2 & 92.8 & \multirow[t]{4}{*}{0.094} \\
\hline African American & 3.3 & 2.2 & \\
\hline Hispanic & 2.7 & 2.2 & \\
\hline Other & 2.8 & 2.8 & \\
\hline \multicolumn{4}{|l|}{ Primary payer } \\
\hline Medicare & 45.6 & 53.7 & \multirow[t]{4}{*}{$<0.001$} \\
\hline Medicaid & 4.6 & 1.6 & \\
\hline Private insurance & 46.2 & 41.2 & \\
\hline Other & 3.6 & 3.5 & \\
\hline Complex cases $†$ & 27.3 & 21.7 & $<0.001$ \\
\hline Revision cases & 5.2 & 3.9 & 0.008 \\
\hline \multicolumn{4}{|l|}{ Preop diagnosis } \\
\hline Acquired postural kyphosis & 8.1 & 7.9 & \multirow[t]{5}{*}{$<0.001$} \\
\hline $\begin{array}{l}\text { Kyphosis not elsewhere } \\
\text { classified }\end{array}$ & 5.3 & 3.1 & \\
\hline Idiopathic scoliosis & 57.7 & 63.2 & \\
\hline $\begin{array}{l}\text { Scoliosis not elsewhere } \\
\text { classified }\end{array}$ & 26.2 & 23.9 & \\
\hline Other & 2.7 & 1.9 & \\
\hline
\end{tabular}

* Values are expressed as percentages unless stated otherwise.

$\dagger$ Complex cases included those with arthrodesis of 8 or more vertebral segments and/or cases of osteotomy.

TABLE 2. Outcomes of patients undergoing surgery for ASD at teaching versus nonteaching hospitals between 2002 and 2011

\begin{tabular}{lccc}
\hline \multicolumn{1}{c}{ Parameter } & $\begin{array}{c}\text { Teaching } \\
\text { Hospital }^{*}\end{array}$ & $\begin{array}{c}\text { Nonteaching } \\
\text { Hospital* }\end{array}$ & p Value \\
\hline No. of cases & 4650 & 2953 & \\
\hline LOS in days, average \pm SD & $7.0 \pm 7.3$ & $5.2 \pm 3.9$ & $<0.001$ \\
\hline Overall complications & 47.9 & 49.8 & 0.114 \\
\hline Procedure-related complications & 40.8 & 42.8 & 0.078 \\
\hline Mortality $†$ & 0.4 & $0.4 \dagger$ & 0.210 \\
\hline
\end{tabular}

* Values are expressed as percentages unless stated otherwise.

$\dagger$ The NIS does not allow publication of values $\leq 10$; therefore, 11 was used as the minimum value for mortality. 
TABLE 3. Specific complications in teaching versus nonteaching hospitals in descending order of frequency

\begin{tabular}{lrcr}
\hline \multicolumn{1}{c}{ Complication } & $\begin{array}{c}\% \text { at } \\
\text { Teaching } \\
\text { Hospital }\end{array}$ & $\begin{array}{c}\text { \% at } \\
\text { Nonteaching } \\
\text { Hospital }\end{array}$ & p Value \\
\hline Acute posthemorrhagic anemia & 33.5 & 36.8 & 0.003 \\
\hline Respiratory complication & 9.1 & 7.6 & 0.020 \\
\hline Implant-related complication & 7.8 & 6.9 & 0.156 \\
\hline Incidental durotomy & 4.4 & 5.7 & 0.007 \\
\hline Hemorrhage or hematoma & 3.3 & 2.8 & 0.202 \\
\hline Accidental puncture & 3.3 & 2.7 & 0.152 \\
\hline Acute kidney injury & 2.4 & 2.2 & 0.495 \\
\hline Pneumonia & 2.1 & 2.5 & 0.243 \\
\hline Deep vein thrombosis & 1.5 & 0.5 & $<0.001$ \\
\hline Neurological complication & 1.6 & 1.1 & 0.067 \\
\hline Wound complication & 1.2 & 0.6 & 0.020 \\
\hline Myocardial infarction & 0.7 & 0.6 & 0.733 \\
\hline Pulmonary embolism & 0.3 & 0.5 & 0.213 \\
\hline Postoperative shock & $0.2^{*}$ & 0.0 & 0.287 \\
\hline latrogenic stroke* & $0.2^{*}$ & 0.5 & 0.616 \\
\hline Pancreatitis* & $0.2^{*}$ & 0.4 & 1.00 \\
\hline The & & &
\end{tabular}

* The NIS does not allow publication of values $\leq 10$; therefore, 11 was used as the minimum value for these complications.

Following a multivariable logistic regression analysis (after controlling for patient age, comorbidities, primary payer, case complexity, revision status, and diagnosis), having ASD surgery at a teaching hospital was associated with significantly lower odds of developing a postoperative complication (OR 0.89, 95\% CI 0.82-0.98; $\mathrm{p}=0.030$ ). However, teaching status was not significantly associated with in-hospital mortality (OR 1.7, 95\% CI 0.73-4.3; p = $0.210)$. The factors most strongly associated with complication development included coagulopathy (OR 4.3; 95\% CI 3.5-5.3), revision procedures (OR 3.4, 95\% CI 2.6-4.4; $\mathrm{p}<0.001$ ), and complex procedures (OR 2.1, 95\% CI 1.92.4; p < 0.001) (Fig. 2).

\section{Complex Case Subanalysis}

A total of $25.1 \%$ of cases were classified as complex, involving osteotomy and/or fusion of 8 or more spinal segments. As mentioned above, the proportion of patients with complex procedures was significantly higher in the teaching hospital group (27.3\%) compared with the nonteaching hospital group $(21.7 \%, \mathrm{p}<0.001)$. A multivariable analysis performed only on complex cases revealed that teaching hospitals had a significantly reduced risk of complication development (OR 0.58, 95\% CI 0.47-0.72; p $<0.001)$ compared with nonteaching hospitals.

\section{Discussion}

Teaching hospitals are an important part of any health care system. These hospitals provide training for future health care professionals, conduct research, provide care to uninsured populations, and serve as referral centers for

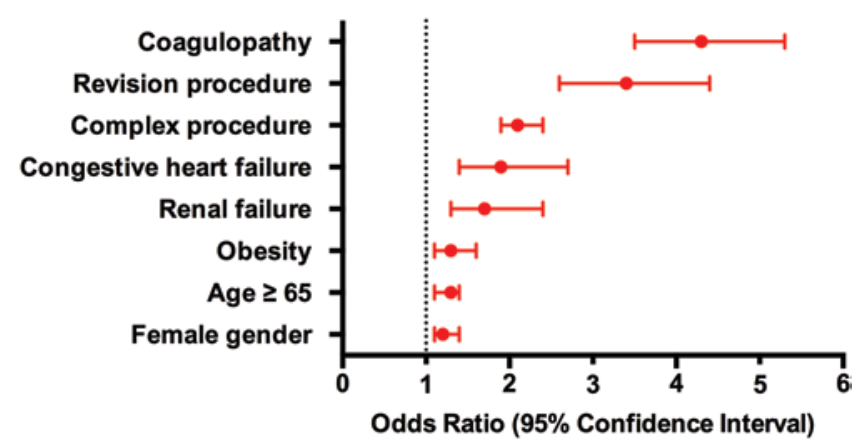

Coagulopathy
Revision procedure
Complex procedure
Congestive heart failure
Renal failure
Obesity
Age $\geq 65$
Female gender

OR $4.3(95 \% \mathrm{Cl}, 3.5$ - 5.3; $\mathrm{p}<0.001)$ OR $3.4(95 \% \mathrm{Cl}, 2.6-4.4 ; \mathrm{p}<0.001)$ OR $2.1(95 \% \mathrm{Cl}, 1.9-2.4 ; \mathrm{p}<0.001)$ OR $1.9(95 \% \mathrm{Cl}, 1.4-2.7 ; \mathrm{p}<0.001)$ OR $1.7(95 \% \mathrm{Cl}, 1.3-2.4 ; \mathrm{p}<0.001)$ OR $1.3(95 \% \mathrm{Cl}, 1.1-1.6 ; \mathrm{p}=0.001)$ OR $1.3(95 \% \mathrm{Cl}, 1.1-1.4 ; \mathrm{p}=0.006)$ OR $1.2(95 \% \mathrm{Cl}, 1.1-1.4 ; \mathrm{p}<0.001)$

FIG. 2. Forest plot showing independent risk factors for complication development in patients undergoing surgery for ASD. Figure is available in color online only.

complex cases. ${ }^{6,10,24}$ However, research has suggested that not only are surgical outcomes between teaching and nonteaching hospitals different, but that patients treated for degenerative spine conditions at teaching hospitals may in fact have higher inpatient morbidity. ${ }^{6,12}$ For example, a study by Fineberg et al. examined outcomes of 212,385 cervical spine operations for degenerative disease $(54.6 \%$ performed at teaching hospitals), finding that the rate of inpatient morbidity was 24.7 per 1000 versus 17.4 per 1000 patients in teaching and nonteaching hospitals, respectively. ${ }^{6}$ Similarly, a study by Nandyala et al. examined 658,616 patients who underwent surgery for lumbar degenerative disease and found significantly higher rates of pulmonary embolism, deep vein thrombosis, infections, and neurological complications in teaching hospitals. ${ }^{12}$ Both of these studies attributed these findings to a higher case complexity and worse preoperative condition of patients treated at teaching hospitals.

In this study, we sought to investigate the effect of teaching status on outcomes after surgery for ASD. These operations are usually performed in older patients; require instrumentation of multiple spinal segments; and carry important risks such as neurovascular injury, high blood loss, instrumentation misplacement/failure, need for revision surgery, and systemic medical complications. ${ }^{22}$ Thus, we hypothesized that outcomes would be different between teaching and nonteaching hospitals. Following data analysis, our study found that patients treated at a teaching hospital had a complication rate of $47.9 \%$ compared with $49.8 \%$ at nonteaching hospitals ( $\mathrm{p}=$ 0.114). Although this crude rate difference appears small and nonsignificant, a multivariable analysis revealed an $11 \%$ decrease in odds (OR 0.89 ; $95 \%$ CI $0.81-0.98$ ) of developing a complication for patients treated at a teaching versus a nonteaching hospital. Importantly, this analysis controlled for operative parameters such as number of fused segments, osteotomy, and revision procedures, as 
well as patient characteristics such as age, sex, and comorbid conditions.

Commensurate with our findings, other studies have found better outcomes in teaching hospitals for more complex procedures such as lung cancer resection, abdominal hysterectomy, pancreatic resection, hepatic resection, and esophageal resection. ${ }^{5,8,11}$ Given that ASD surgery may be considered more complex than an anterior cervical discectomy and fusion or a posterior lumbar laminectomy and fusion, this could explain the conflicting results with those of the studies by Fineberg et al. and Nandyala et al., which examined the latter procedures. Furthermore, 4.7\% of all procedures in our study were found to be revision procedures; $21.0 \%$ involved fusion of 8 or more segments; and $25.1 \%$ were categorized as complex ASD procedures, involving fusion of 8 or more segments or osteotomy. In fact, a separate subanalysis of only complex cases revealed that hospital teaching status was also significantly associated with reduced odds of complication development (OR 0.58 ; 95\% CI $0.47-0.72$ ), suggesting that patients treated at academic centers may in fact have improved short-term outcomes.

The most common inpatient complication in the present study was acute posthemorrhagic anemia, which occurred in more than one-third of patients (34.8\%). Blood loss during ASD surgery may be greater than $4 \mathrm{~L}$ in cases involving osteotomy, ${ }^{7}$ potentially leading to organ damage, coagulopathy, infections, longer hospital stays, and higher costs. ${ }^{16}$ Recently, a double-blinded randomized controlled trial showed that antifibrinolytics significantly reduced blood loss in posterior ASD surgery compared with placebo. ${ }^{16}$ Not surprisingly, coagulopathy was the strongest independent factor associated with development of any postoperative complication (OR 4.2). This was followed by revision procedures (also associated with higher blood loss) ${ }^{23}$ and complex procedures. Other factors such as congestive heart failure, renal failure, age $>65$ years, female sex, and obesity also increased the odds of inpatient morbidity.

When comparing specific complications between teaching and nonteaching hospitals, acute posthemorrhagic anemia and incidental durotomies were both more common in nonteaching hospitals (36.8\% vs $33.5 \%$ and $5.7 \%$ vs $4.4 \%$, respectively). The precise reason for this is unknown, but it has been suggested that teaching hospitals benefit from increased surgeon experience, advanced training, availability of intensive care unit staffing, availability of diagnostic technology, and other factors. ${ }^{5}$ Last, mortality was not significantly different between groups $(0.4 \%$ in teaching hospitals and $<0.4 \%$ in nonteaching hospitals, $\mathrm{p}=0.210$ ), which was consistent with findings in previous studies. ${ }^{6,12}$

Although the results of the present study suggest that ASD surgery may be safer in teaching versus nonteaching hospitals, redirecting patient care may not be entirely feasible, and more studies are needed before definitive conclusions can be made. Additionally, the results presented herein are limited by the retrospective nature of the study, as well as a potential source of coding/reporting bias from using the NIS. Although an attempt to control for case complexity was made by classifying a procedure as complex if osteotomy or fusion of 8 or more spinal levels was performed, other data such as Cobb angles, sagittal vertical axis, sacropelvic parameters, and curve types are not available within the NIS. Given that data on complications are based on coding, this carries the risk of upcoding bias. This phenomenon consists of hospitals changing their coding practices to capture more baseline patient comorbidities and complications, in an attempt to maximize reimbursements. ${ }^{2}$ On the other hand, given that the NIS is only an inpatient database, complications that may occur outside the hospital are not captured. Despite these limitations, various studies have examined short-term outcomes after scoliosis surgery using the NIS, $4,13,14,21$ and most of their findings have been consistent with other multicenter collaborations, particularly in regard to rates of perioperative complications. Nonetheless, the findings in the present study may lead to future multicenter prospective studies on the matter, with longer-term follow-ups and patientreported outcomes.

\section{Conclusions}

The findings in this study suggest that patients who undergo ASD surgery at a teaching hospital may have significantly decreased odds of developing a postoperative complication compared with patients treated at a nonteaching hospital (11\% odds reduction). Coagulopathy, revision, and complex procedures, among other factors, may all lead to increased risk of complication development, particularly acute posthemorrhagic anemia. Future research on the long-term implications of surgically treating patients for ASD at a teaching versus nonteaching hospital is needed before definitive conclusions can be established.

\section{References}

1. Charosky S, Guigui P, Blamoutier A, Roussouly P, Chopin $\mathrm{D}$ : Complications and risk factors of primary adult scoliosis surgery: a multicenter study of 306 patients. Spine (Phila Pa 1976) 37:693-700, 2012

2. Cram P: Assessing hospital productivity. Health Aff (Millwood) $34: 1069,2015$

3. Daubs MD, Lenke LG, Cheh G, Stobbs G, Bridwell KH: Adult spinal deformity surgery: complications and outcomes in patients over age 60. Spine (Phila Pa 1976) 32:22382244, 2007

4. Diebo BG, Passias PG, Marascalchi BJ, Jalai CM, Worley NJ, Errico TJ, et al: Primary versus revision surgery in the setting of adult spinal deformity: a nationwide study on 10,912 patients. Spine (Phila Pa 1976) 40:1674-1680, 2015

5. Dimick JB, Cowan JA Jr, Colletti LM, Upchurch GR Jr: Hospital teaching status and outcomes of complex surgical procedures in the United States. Arch Surg 139:137-141, 2004

6. Fineberg SJ, Oglesby M, Patel AA, Pelton MA, Singh K: Outcomes of cervical spine surgery in teaching and nonteaching hospitals. Spine (Phila Pa 1976) 38:1089-1096, 2013

7. Hu SS: Blood loss in adult spinal surgery. Eur Spine J 13 (Suppl 1):S3-S5, 2004

8. Juillard C, Lashoher A, Sewell CA, Uddin S, Griffith JG, Chang DC: A national analysis of the relationship between hospital volume, academic center status, and surgical outcomes for abdominal hysterectomy done for leiomyoma. $\mathbf{J}$ Am Coll Surg 208:599-606, 2009

9. Kostuik JP, Hall BB: Spinal fusions to the sacrum in adults with scoliosis. Spine (Phila Pa 1976) 8:489-500, 1983 
10. Levin R, Moy E, Griner PF: Trends in specialized surgical procedures at teaching and nonteaching hospitals. Health Aff (Millwood) 19:230-238, 2000

11. Meguid RA, Brooke BS, Chang DC, Sherwood JT, Brock MV, Yang SC: Are surgical outcomes for lung cancer resections improved at teaching hospitals? Ann Thorac Surg 85:1015-1025, 2008

12. Nandyala SV, Marquez-Lara A, Fineberg SJ, Hassanzadeh H, Singh K: Complications after lumbar spine surgery between teaching and nonteaching hospitals. Spine (Phila Pa 1976) 39:417-423, 2014

13. Paul JC, Lonner BS, Goz V, Weinreb J, Karia R, Toombs CS, et al: Complication rates are reduced for revision adult spine deformity surgery among high-volume hospitals and surgeons. Spine J 15:1963-1972, 2015

14. Paul JC, Lonner BS, Toombs CS: Greater operative volume is associated with lower complication rates in adolescent spinal deformity surgery. Spine (Phila Pa 1976) 40:162-170, 2015

15. Paulus MC, Kalantar SB, Radcliff K: Cost and value of spinal deformity surgery. Spine (Phila Pa 1976) 39:388-393, 2014

16. Peters A, Verma K, Slobodyanyuk K, Cheriyan T, Hoelscher $\mathrm{C}$, Schwab F, et al: Antifibrinolytics reduce blood loss in adult spinal deformity surgery: a prospective, randomized controlled trial. Spine (Phila Pa 1976) 40:E443-E449, 2015

17. Schwab F, Dubey A, Gamez L, El Fegoun AB, Hwang K, Pagala M, et al: Adult scoliosis: prevalence, SF-36, and nutritional parameters in an elderly volunteer population. Spine (Phila Pa 1976) 30:1082-1085, 2005

18. Simmons ED Jr, Kowalski JM, Simmons EH: The results of surgical treatment for adult scoliosis. Spine (Phila Pa 1976) 18:718-724, 1993

19. Smith JS, Shaffrey CI, Berven S, Glassman S, Hamill C, Horton W, et al: Operative versus nonoperative treatment of leg pain in adults with scoliosis: a retrospective review of a prospective multicenter database with two-year follow-up. Spine (Phila Pa 1976) 34:1693-1698, 2009

20. Vartak S, Ward MM, Vaughn TE: Do postoperative compli- cations vary by hospital teaching status? Med Care 46:2532,2008

21. Worley N, Marascalchi B, Jalai CM, Yang S, Diebo B, Vira S, et al: Predictors of inpatient morbidity and mortality in adult spinal deformity surgery. Eur Spine J 25:819-827, 2016

22. Youssef JA, Orndorff DO, Patty CA, Scott MA, Price HL, Hamlin LF, et al: Current status of adult spinal deformity. Global Spine J 3:51-62, 2013

23. Zheng F, Cammisa FP Jr, Sandhu HS, Girardi FP, Khan SN: Factors predicting hospital stay, operative time, blood loss, and transfusion in patients undergoing revision posterior lumbar spine decompression, fusion, and segmental instrumentation. Spine (Phila Pa 1976) 27:818-824, 2002

24. Zimmerman JE, Shortell SM, Knaus WA, Rousseau DM, Wagner DP, Gillies RR, et al: Value and cost of teaching hospitals: a prospective, multicenter, inception cohort study. Crit Care Med 21:1432-1442, 1993

\section{Disclosures}

Dr. Sciubba is a consultant for Medtronic and received an honorarium from DePuy-Synthes for a Fellows Course in 2015.

\section{Author Contributions}

Conception and design: Sciubba, De la Garza-Ramos. Acquisition of data: De la Garza-Ramos. Analysis and interpretation of data: De la Garza-Ramos, Jain, Kebaish, Bydon, Passias. Drafting the article: all authors. Critically revising the article: all authors. Reviewed submitted version of manuscript: Sciubba, De la Garza-Ramos. Approved the final version of the manuscript on behalf of all authors: Sciubba. Statistical analysis: De la GarzaRamos. Study supervision: Sciubba, Kebaish, Passias.

\section{Correspondence}

Daniel M. Sciubba, Department of Neurosurgery, The Johns Hopkins Hospital, 600 N. Wolfe St., Meyer 5-185, Baltimore, MD 21287. email: dsciubb1@jhmi.edu. 